\title{
Education of a Human Being as a Possibility for Life Self-fulfillment: Systemic and Anthropologic Approach
}

\author{
Irina Olegovna Loginova \\ V.P. Astafyev Krasnoyarsk State Pedagogical University, Russia
}

\begin{abstract}
The paper considers the phenomenon of «education of a human being» as a possibility for life selffulfillment in the context of a systemic and anthropologic approach. There are various points of view on education as the problem of self-organization for the psychological systems in the article: education as adaptation, education as self-regulation, and education as self-organization. Human being's educational opportunities are considered as an individual life strategy aimed at life self-fulfillment.
\end{abstract}

\section{Introduction}

Considerable changes in psychological science regarding the transfer from "psycho psychology" to "psychology of a human being" [1] have given rise to crucially new educational trends.

Such changes in the society result in the expansion of the scientific concepts disclosing the variety of human recourses as non-realized possibilities that require realization. "Education" and "life selffulfillment" of a human being are referred to such concepts. The reference to the latter is connected with the fact that issues on developing a human nature mainly in a human being together with the mechanisms for human being education [2] that are considered by the modern psychological science is the issue on the method for presenting oneself to the world and finding new possibilities to oneself through that. The paradigm under development in the psychological science that is characterized by the system redefining the subject of the science and that leads scientists to a human being as a self-organized system explains the role of the psychological in the development of a human being through perception of a mission and role of a human being as a superior system defining from "above" the possibilities of the psycho and its role in the lifechanging processes. Thus, the understanding of a human being in accordance with the modern trends of development for the psychological science allows approaching the issues of a human being's education as a possibility for the life self-fulfillment.

These trends are related to the term itself, which is stated by I.Ya. Lerner: "Education can not be defined precisely ... but ... alongside with that ... it is a phenomenon of activity regarding determination and formation of the image of a human being and his place in the world" [3].
The term education is represented in Russian psychological and pedagogical literature as follows:

- education is a space for complicated and tense work aimed at formation of multi-dimensional consciousness and ability for self-determination in history, culture, and later on in profession triggering the student's "self" in the form of personal and professional self-development.

Analyzing the above mentioned definition one may say that "education" has got three main meanings:

1) personal assets, a system of ideas and concepts in the subjective personal space guiding one's behavior;

2) a process of personality introduction to culture, establishment and development of education as personal assets and whole cultural environment;

3) a special social institute (system of education), one of the components of cultural environment of a human being developing and applying a range of measures organizing and ruling education as a process of personality introduction to culture.

New values that appeared in education such as selfdevelopment, self-design, self-education, selfrealization, creativity and etc. allowed extending the understanding of world space of a human being considerably to a self-organizing system. In this respect, such terms as "opportunities extension", "personal potential actualization", and "self-evolution" combining the history of human development, its present and future are considered as synonyms to education. That is why the term "education" implies the continuity of the process, establishment of various human manifestations in his life activity or a human being on the whole. V.E. Klochko gives a new meaning to the category and defines education as "a consistent on-going sovereignization process concurrent with the establishment of a multidimensional world of a human being with a complete set of value-sense allowing for active and selective sovereign behavior” [2].

\section{Education as systems self-organization problem}

All opinions existing in psychology at present regarding education of a human being as a problem of psychological systems self-organization can be relatively divided into three groups in the course of the analysis [4]. 


\subsection{Education as adaptation}

The first group includes psychological theories of the so-called adaptive type. Despite of the fact that the representatives of this group define a human being as a self-organizing system, they constrict its development to adaptation or conformity to the external environment. Human self-development is connected to the improvement of psychological mechanisms of life activity regulation and is consciously grounded on individual abilities of a human being to adapt to changing environmental conditions during regulation process, on personal qualities guiding one's social behavior and on the ability to assign universal human values, social standards and attitudes that organize human life.

The understanding of psychological adaptation as adaptive process is related to the protection of organism and psycho against destructive impact of the environmental factors. Social and psychological adaptation is a continuous process of an individual's adaptation to the environmental conditions as well as the result of this process. Although social adaptation is a constantly-going process, this term however is often connected to the period of significant changes in the person's activity or environment.

Another important aspect of social adaptation is taking a certain social role by a person. Due to this, social adaptation is referred to as one of the main social and psychological mechanisms of personal socialization. The success of adaptation depends very much upon the adequate self-perception and understanding of one's social connections by the person: distorted or underdeveloped opinion about oneself results in various adaptation problems.

The problem of social and psychological adaptation also covers such terms as "adaptiveness" and "unadaptiveness" that are characterized by achievement or non-achievement of the set aims in the process of life activity correspondingly.

Main types of a person's adaptation process are formed depending upon the structure of the person's needs and motives and are as follows:

1) active type is characterized by mainly active influence on social environment;

2) passive type is characterized by passive conform acceptance of aims and value orientation of the group.

Psychological theories belonging to the first group pay attention to the stability as a characteristic of personality. Numerous studies of this type are devoted to the stress resistance, emotional stability, tolerance as conflicts resistance etc. as characteristic features of a personality. The representatives of this opinion point out that a personality can resist negative influence and perform reasonable constructive changes in the environment due to psychological stability, thus, providing for the efficiency of life and activity, development and improvement of a personality as well as preservation of psychic health.

Thus, a self-organizing origin of psychological systems is considered by the representatives of the first group to be connected to the system's ability to adapt to environmental conditions which guarantees the system's stability at all its levels under changing external conditions. Education of a human being in the context of the research held by this group of researches is a developing process of person's adaptation to constantly changing environmental condition at all levels of psychological system organization. Here one may speak about unilateral "adaptation” of a person: adaptation of internal to external which determines if a person's life activity is a success that is why "education" here means "adaptation" and “conformity”.

\subsection{Education as self-regulation}

The second group includes psychological theories considering self-evolution and self-organization of a human being as a process happening due to innovations that are "at the same time conditional and conditioning” for human development [5]. The representatives of this group believe that innovations are formed on the basis of a number of personality's characteristics such as ability to keep and preserve all positive in one's history, accumulate the results of the development, keep up to date one's potential mental content, create something new in the world and in oneself extending the sphere of the potential [6].

In case of self-regulation the system functions in the following way: regulation effect is formed by collaboration of all system's components and due to this requires no constant control, thus being more reasonable as far as resources are concerned [7]. Researches sharing this approach define self-regulation as a systematic process including dynamic actions of a person (here these theories are superior to the theories of the first group) aimed at adaptation to constantly changing environmental conditions. Scientists underline the cyclical pattern of this process.

Ideas about self-regulation developed in the laboratory for self-regulation of Psychological Institute of the Russian Academy of Education are distinguished through their considerable complexity in respect of internal structure of the self-regulation components under study, thus, present the direct consequence of the initial personal orientation of the research. Foe example, the planning stage defines up to 6 functions (target setting, strategy determination, and determination of effectiveness, subjective value, expectation and process-orientation). At present, researches' focus is transferred from general issues of self-regulation structure to the development of its cognitive and personal aspects, to the understanding of the fact that various personal and cognitive structures are backed by specific structures of individual subjective activity organization.

At the same time Russian studies differ from Western psychology in a way that the former develop from general theory of structure and functions of conscious self-regulation to the study of personality and individual manifestations and forms of regulation, whereas western theories start from study of personality and separate sides of regulation and moves to an integral self-regulation theory and understanding 
of the fact that regulation consciousness is a very important personal dimension.

Despite of certain differences in approaches to the study of human self-regulation phenomenon, all scientific works demonstrate a common view of regulation as a most general function of psychic activity specific for a human-being allowing a person to act as a creator, executor, supervisor and judge of one's own activity, deeds, and life in general. Selfregulation is an embodiment of a general human ability to be a subject of one's conscious activity reflecting the abilities of his psychics and realized in a numerous variety of acts providing for the actual relations of the subject with various phenomena and manifestations of reality. Self-regulation is represented by two meanings: as a general ability for organization of activity of a human being acting as a subject of one's own activity and as a process of realization of the abovementioned ability in separate phenomena of activity, behavior and communication. However, Russian scientists point out that the ability of self-regulation is becoming a general ability only upon completion of formation of an integral conscious self-regulation system, formation of its conscious control and its introduction to the internal plan of actions [8].

The subjectness of a person is developed and is becoming more sufficient in the process of further improvement of the self-regulation system, thus giving ground to certain personal innovations: confidence, self-sufficiency, responsibility, and initiative in all spheres of personal self-determination.

Therefore, according to the second group representatives' opinion, the self-regulation is one of the innovations considered in the framework of the "human being" psychological system, "regulating" both his relations with the world and formation of other manifestations of self- (self-cognition, selfdetermination, self-evolution, self-realization, selfactualization and etc.). Self-organization of the psychological system is grounded on the basis of the human being's movement while performing individual vital activities at different levels aiming to accumulate innovations, of which central is psychic self-regulation. Within the context, education is "acquiring" oneself in the process of life (own abilities and potential for development) which occurs in the acts of interaction between "inner" and "external" resulting in innovations required for further development of psychological system.

\subsection{Education as self-organization}

The third group contains theories that understand the self-organizing system as the system that preserves its sustainability due to interaction with the external environment and is able to the independent reconstruction of its structure under the influence of the external environment as well as the processes going in the system itself. The conditions for the development of self-organizing systems as well as basic regularities and such mechanisms as differentiation, integration, hierarchization of elements, self oscillations and feedbacks are provided by the action of the strategic factor. The representatives of this group believe that emerging of any self-organizing system, i.e. cluster of elements is caused by one and only reason: acquiring higher tolerance by these elements. The reason and, therefore, the objective of the elements cluster is the strategic factor (according to the authors of these theories and within the context defined by us it is a human being) due to whom the unity emerges for higher tolerance of its component parts. The developed unity, the system, can perform its main function subject to reaching the identity with the elements that formed it and that represent the selforganizing systems of a smaller size. This provides for evolutionary systems development that is posted as the ontological basis for synergetics and revealing the essence of the total philosophical principle "everything is in everything" that was developed due to works of P.T. de Chardin and others. Maintaining the attitude that "a human being came into existence and historically grows up from the whole material and the whole life" [9] P.T. de Chardin proves in his work "Christ in Evolution" that the evolution has an irreversible nature saying that the life has a certain logics from the moment of its germ and up to the present: initially setting the requirement to all living beings to survive by lucky chance or by any other way, and then gradually comes to setting the requirement to improve the world and then oneself. According to the scientist, this is the logics that stipulated for the ways of life action. Out of these one can name abundance that is reached by way of masses effect; inventiveness that defines world freedom due to its variability; indifference expressing itself in the contradiction "between the element that emerged out of the multitude and the multitude that continuously emerges out of the element in the evolutionary process" [9]. In this respect, the sufficient characteristic of the evolutionarity is the simultaneous and uniform nature of the Universe "drifting" in the direction of supercomplexity, super-focus and super- consciousness due to which the "human being phenomenon gains the specific and related sense” [9].

V.G. Budanov contributing to this opinion writes that "within the processes of self-regulation there is a qualitative compression of information as a result of quickly flowing process of natural self-selection that is difficult to trace; the product of these process being the order parameter able to be observed" [7]. Within the context of the third group theories, the subsystems are interrelated and interdependent; therefore, the peculiarities of the structure as well as the quality of organization of one of the subsystems can depend on the structure and quality of the organization of the other. The transition of quality features from one subsystem to the other depends on the peculiarities of organization of the system correlations and to be more particular, the quality features of these subsystems. In this respect E. Laslo remarked that "some systems are always requiring the medium of a particular type; it must be a medium consisting flows where the rich and continuous energy source is expanding the system" [10]. This point of view in its essence complies with the opinion expressed by A.G. Asmolov who pointed 
out that qualities of a human being that characterize one as the system element "open" only in the conditions of interactions within these or those systems [11]. This is why the main strategic factor of a human being development can be considered a human being itself, while the mechanisms of self-development can be self-planning, self-regulation and self-organization [12].

Special emphasis shall be laid to those psychological theories in the third group that employ the self-regulation principle alongside with the heterostasis principle formulated by V.E. Klochko. The question is the highest level of systematic organization of a human being - "development going beyond the standards through the standard-setting” [13]. The representatives of this group point at the universal feature of self-organizing systems of any nature, i.e. self-determining that allows readdressing the responsibility for the choice from the external causation or necessity to a human being itself. This feature of a human being as a self-organizing system allows to consider the latter as the one able to "set oneself at the "limit" ... that symbolizes for him the readiness to part with oneself as one had been before the "event", i.e. to change oneself" [14] acting not as a simple chain in the evolution but as the one responsible for the evolution.

Thus, having defined a human being as a selforganizing system we can detach the process of the system's production and generation of the new that is immediately implemented into further determination of the system self-organization as a form where its development is performed. Thus, V.Ye. Klochko indicates that through the acts of such generation (the system's generating the new) the self-organized system obtains the possibility to influence itself. According to him, this is "the principle of the system determination without which it is not possible to explain the mechanisms of the system self-organization and selfdevelopment as a form where self-organization is revealed" [13].

We focus attention to the fact that the education of a human being as a self-organization is possible in the space defined by the unity of the world and the human being itself since "beyond us the world is mutual propensity without succession, we have succession inside us without external sets-string", and only the unity of these beginnings makes "the process of organization and interpenetration" [14]. Within the context, the education of a human being can be considered as the problem of self-organization of one's living space (according to M.K. Mamardashvili, without a human being "the world shall lack order, truth and beauty"), since the life of a human being itself is like a trajectory of movement of the selforganizing system within the time and space.

We believe that the third group of the research has a direct access to the research of the human being education that is understood as the expansion of the possibilities since it considers the problems of emerging, existing, transformation, development and self-development of a human being in their unity. In the framework of this research, there is a possibility to consider the issues of individual educational strategies defining the direction vector and content of a human being education.

\section{Education as human opportunity for life self-fulfillment}

Having analyzed the abovementioned opinions, it is worth underlining that the problematic nature of understanding the human being's education as the manifestation of the psychological system selffulfillment is in the fact that the "self-fulfillment" conscious of psychologists scientists has not developed the unified approaches to realize the phenomena of psychological reality, therefore, the "range" of selffulfillment mechanisms for the systems development is considerably wide: from the adaptation to the selforganizati0on itself. The ideas on a human being as the carrier of a psycho as the "adaptation organ" [15] cannot approach the science as a problematic sphere for considering a human being as a self-organized system. Remaining in the sphere of classical ideas the psycho is successfully coping in the conditions of adaptation to the changing environment without a human being's participation.

Ideas on a human being as the subject of own life activity enabled with the possibilities of self-control though they mark activity of a human being as a vital condition for his (self) developments, but "do not rise above” a non-classical ideal of rationality. Claiming for research of a phenomenon for a human being's "education" it is necessary to leave in the conditions of a post-non-classical ideal of the rationality providing understanding of a human being as a self-organized system. Besides, statement of such a problem requires certain methodological position adequate to the set problem.

Such methodological basis is the systemic anthropological psychology [16, 17]. Within the concepts of systemic anthropological psychology a human being appears as a difficult self-organized psychological system opened both to the society and to the objective (natural, physical, "real") environment [15]. It is important that the given idea on a human being allows to look at him (a human being) "through a prism of formation and to make out it in it as a complete self-organized system, progressive and natural complication of systemic organization is the basis of its steady life" [15, 17]. This system "extends and becomes complicated due to interaction with external, thus, making it internal” [15] continuously changing and developing oneself. M.K. Mamardashvili's opinion opens this constant selfchange of a human being under the influence of those unknown "external" conditions in which he lives and operates, acting as "unknown person" for oneself and revealing all new sides in oneself: "A human being unlike an animal is a being facing unknown, either through search, or through development in the direction to the unknown. Only for a human being there is the unknown. Including as well since no limiting measures are set for a human being in 
advance. There is no measure through which we would define that this is a human being. ... And the most beautiful show in a human being is when a human being does something at a limit of what a human being is capable of in general. As the limit is unknown in advance it is necessary to set oneself on a map and to go" [18]. This conveys true "dramatic nature" of human life being constant negation of the today's for the sake of the tomorrow's. Therefore, the logic of human life is that being born as a possibility to become a human being in the course of a life he (a human being) carries out this possibility directing into the future and due to that he (a human being) cannot stop in the development (self-development).

Within the context of the concept of "a human being" acting in the logics of the present research as theoretically understood subject of psychological knowledge, as a whole, and designated as "starting point" of systemic anthropological psychology, in particular, education as a possibility of vital selfrealizations gets essential enough shades. Its essence reveals through ability of psychological system to selforigin, self-development, and preservation of the organization at change of the internal and external conditions providing transition of systems from one steady state to another with fall of entropy, so increase of level of their organization.

Actually, to understand education of a human being as a product of a human being, his life, means possibility to understand and the person in the course of its vital self-fulfillment [19].

The productivity of vital self-fulfillment of the person depends on many psychological qualities of the person, developing which it increases the efficiency, masters the various forms of self-realization accompanied by different level of expressiveness of aspiration to personal growth and development, characteristics for motivational and needs spheres and statements of a human being to oneself. Along with personal qualities among the factors promoting effective self-realization, it is possible to allocate the high social status and an educational level expanding vital space of a human being.

In our opinion, all these indicators are directly connected with life self-fulfillment of a human being as a specially created attitude with the world around, stating a question on whether the life is what a human being (under the formula "I live") or it that itself is carried out in a human being (under the formula "I have living”). Being a mean of realization of the life project (obtaining education can be both a component of this project and its essence as well) life selffulfillment acts as a special value allowing to set frameworks of the new life standard.

True life self-fulfillment a human being reveals itself in a situation of transfer of possibility in the validity in such a manner that it acts for a human being as realization of responsible possibility as necessities. In respect of responsibility to itself, to own life world, own development as to self-fulfillment the idea of heterostasic system developments "possibility of transformation of the validity - necessity of transformation - the new (transformed) validity” [15] that leads the system to the new standard of living shown in the course of life self-fulfillment of a human being.

That is why in each separate act, action, deed in life activity and life creativity a human being carries out oneself, embodying in life process infinite formation, the vast variety, acting as that infinite number of degrees of freedom which defines boundless possibilities of the person. In a point of coincidence of possibility of the person and validity conditions begins the movement to "a successful life" a human being as a guarantee of achievement of the purpose in realization of each separate action. That is why achievement of the purpose of the person delivers it (a human being) the greatest subjective satisfaction behind which success in a life is covered.

\section{Conclusion}

Conducting research it seemed to us topical to find proof that the orientation of life self-fulfillment as development of a human resource in the course of life coincides with how it was defined by L.S.Vygotsky with reference to development of the higher mental functions and a human being as their systemically important basis: "The whole development is that function development goes from me to I" [20]. Indeed, in the process of education a human being is continuously changing himself generating new parameters of the order leading one to new a qualitatively new level requiring revealing new contradictions between the image of the world and image of the life (as I see the life and the life as it is in reality). These contradictions act as a basis for the life activity as a process of self-generation of chaos of parameters of an order by means of which evolutionary valuable selection, "new-birth" systems as which it is possible to consider as a true source of movement to the life self-fulfillment "opening" variety of semantic shades and contexts of the further movement is realised. Besides, specifics of formation as possibilities of life self-fulfillment in the system-anthropological context set by us acts as creativity in relation to itself which is determined future - the world of its (human being) of the purposes directing activity in the present.

\section{Acknowledgement}

The work has been performed within the framework of the Federal Special Purpose Programme "Scientific and Scientific and Pedagogical Specialists in Innovative Russia” for the years 2009-2013.

The author thanks Professor V. E. Klochko for his very helpful comments on an earlier draft of this manuscript.

\section{References}

[1] V. I. Slobodchikov, "Anthropological principle in psychology of development”, Questions of psychology, 1998, N6, pp. 3-17. 
[2] V.E. Klochko, "Human being as the self-organizing psychological system”, Human being as the self-organizing psychological system: Materials of regional conference, Barnaul, Barnaul State Pedagogical University Publishing House, 2000, pp. 3-7.

[3] I.Ya. Lerner, Philosophy of didactics and didactics as philosophy, Moscow, Education, 1995, p. 49.

[4] I.O. Loginova, Psychology of professional work of the teacher, Krasnoyarsk, V.P. Astafyev Krasnoyarsk State Pedagogical University, 2007.

[5] S.L. Rubinshtein, Human being and the world. Moscow, Nauka, 1997, p.191.

[6] Yu.V. Sharonin, Psychological and pedagogical grounds for developing the qualities of a creative personality in the system of continuous education (synergetic approach), Moscow, Moscow State Industrial University, 1998, p.321.

[7] V.G. Budanov, "Model for the evolution of disciplinary knowledge as the process of interdisciplinary correlation”, Materials of Moscow International Synergetic Forum. Moscow, Institute of Physiology in Russian Academy of Sciences, 1997, pp. 97-103.

[8] O.A. Konopkin, "Mechanisms of conscious selfregulation of a human being's voluntary activity", Subject and personality in the psychology of self-regulation: Collection of scientific papers, Moscow-Stavropol, Psychology Institute of Russian Academy of Education Publishing House, North Caucasus State Technical University, 2007, pp. 12-31.

[9] P.T. de Chardin, The Phenomenon of Man (Le Phenomene humain), Moscow, AST Publishing House, limited liability company, 2002, pp. 495-510.

[10] E. Laslo, Ways leading to the further millennium. Problems and prospective,

http://vivovoco.rsl.ru/VV/PAPERS/HISTORY/ERVI,

Access 12 of June, 2009.

[11] A.G. Asmolov, "Historical and evolutionary approach to understanding the personality: problems and prospects”, Psychological issues, Moscow, 1986, N1, pp. 4-19.

[12] E.A. Semenova, "Acmeological mechanisms of development of a professional's "Self”-concept", Psychological problems of life sense and acme: Materials of symposium XII, Moscow, Psychology Institute of Russian Academy of Education, 2007, pp. 294-296.

[13] V.E. Klochko, Initializing intellectual activity, Thesis of Doctor of Psychological Sciences, Moscow, Moscow State University, 1991, p. 372.

[14] M.K. Mamardashvili, Necessity of self, Moscow, Labirint Publishing House, 1996, p. 430.

[15] V.E. Klochko, Self-organization in psychological systems: problems of creating mental space of a personality (introduction to transspective analysis), Tomsk: Tomsk State University, 2005.

[16] E.V. Galazhinskiy, V.E. Klochko "On principles of systemic anthropological psychology”, Materials of meeting IV of the Russian psychological society, Volume 1, Rostov on Don, 2007. - p. 226.
[17] V. E. Klochko, Systemic anthropological psychology and educational practice // Psychology of education, 2008. No 8. - pp. 9 - 21.

[18] M. K. Mamardashvili, Psychological topology of a way, Saint Petersburg, Russian Christian Humanitarian Institute, 1997.

[19] I. O. Loginova, Psychology of life self-fulfillment, Moscow, Modern humanitarian university, 2009.

[20] L. S. Vygotskiy, Specific psychology of a human being, Moscow, 2003. 